\title{
Phenotyping Asthma and COPD
}

Peter G. Gibson MBBS, FRACP, FThorSoc $1,2,3,4$ and Vanessa M. McDonald PhD, B. Nurs, RN 12,2,3

${ }^{1}$ National Health and Medical Research Council Centre of Excellence in Severe Asthma, University of Netwcastle; ${ }^{2}$ Priority Research Centre for Healthy Lungs,

University of Newcastle; ${ }^{3}$ Hunter Medical Research Institute; ${ }^{4}$ Department of Respiratory and Sleep Medicine, John Hunter Hospital; Newcastle, Australia

\section{ABSTRACT}

Clinical management of asthma and COPD is complex, largely because of the marked heterogeneity observed in these conditions. Phenotyping is a new approach that can assist clinicians. This review seeks to describe an approach to clinical and inflammatory/molecular phenotyping of asthma and COPD. Clinical phenotypes can be considered in the key domain areas of comorbidity, airway, and risk factors. Evidence-based therapy can be linked to each of the components of these airway disease phenotypes. The concept can be extended to identify disease endotypes, where a pathogenic mechanism is linked to a specific treatment, and biomarkers are used to identify endotypes. Eosinophilic inflammation is perhaps the best characterized endotype of airway disease. Molecular endotypes are now also being identified using transcriptomic approaches. Phenotyping asthma and COPD represents a new and potentially effective approach to the management of these heterogeneous airway diseases. (BRN Rev. 2016;2:239-52)

Corresponding author: Peter G. Gibson, peter.gibson@newcastle.edu.au

Key words: Asthma. Chronic Obstructive Pulmonary Disease (COPD). Eosinophil. Phenotype.

\section{Correspondence to:}

Peter G. Gibson

Hunter Medical Research Institute, Faculty of Health and Medicine

The University of Newcastle

Level 2 West Wing, Locked Bag 1000

Newcastle, New Lambton, NSW 2305, Australia

E-mail: peter.gibson@newcastle.edu.au

Received in original form: 19-07-16

Accepted in final form: 15-08-16

DOI: 10.23866/BRNRev:2016-M0030 


\section{INTRODUCTION}

Asthma and chronic obstructive pulmonary disease (COPD) are common non-communicable diseases that cause significant illness burden. COPD is a condition of high and increasing prevalence, affecting approximately $10 \%$ of people over the age of 40 globally $^{1}$, with prevalence continuing to increase with age $^{2}$. In 2010 it was the third leading cause of mortality worldwide ${ }^{3}$. Asthma similarly effects approximately $10 \%$ of the world's population, and can be diagnosed at any age, including the elderly. Mortality from asthma remains a problem and the risk of dying from asthma increases with age, with most deaths occurring in those over the age of 65 years ${ }^{4}$.

Heterogeneity in terms of airway pathophysiology, comorbidity, risk factors and behavioural characteristics exists in both asthma and COPD; accordingly, the management of these conditions can be complex ${ }^{4,5}$. In an attempt to improve outcomes for patients with asthma and COPD, a phenotyping approach has been proposed ${ }^{5-8}$. This approach classifies patients into subgroups according to either prognosis or treatment response; this then enables the application of targeted or individualized therapies to improve outcomes ${ }^{4,5}$.

This review discusses the clinical, inflammatory, and molecular phenotypes identified in asthma and COPD and offers an approach to phenotyping that can be implemented in the clinic.

\section{DEFINITIONS}

A phenotype is defined as "the set of observable characteristics of an individual resulting from the interaction of its genotype with the environment". This definition can be limited when applied to clinical practice because it doesn't necessarily determine that the identification of a phenotype has any clinical use at all! In order to increase the utility of phenotyping, the additional concepts of a clinical phenotype and of an endotype have been developed.

A clinical phenotype is defined as "a single or combination of disease attributes that describe differences between individuals with COPD as they relate to clinically meaningful outcomes like symptoms, exacerbations, response to therapy, rate of disease progression or death" ${ }^{\prime \prime}$. A key and important aspect of this definition is that it lifts the recognition of a phenotype beyond any recognizable characteristic, and extends it to a characteristic that is clinically important. This adds significantly to the clinical utility of phenotypic characterization in asthma and COPD.

An endotype is "a subtype of a condition, which is defined by a distinct functional or pathobiological mechanism" (https://en. wikipedia.org/wiki/Endotype). Implicit in this description is the recognition of a key mechanistic pathway that is operating in the individual with the condition. The utility of the endotype concept is that it allows recognition of specific biomarkers and therapeutics that can be used to identify and treat the endotype ${ }^{10,11}$. An inflammatory or molecular endotype is a disease subtype of a condition or disease that has specific inflammatory or molecular characteristics indicating an underlying pathobiological pathway. 


\section{APPROACHES TO CLINICAL PHENOTYPING}

The approach to phenotyping needs to consider the variables assessed, the study design used to identify the phenotype, and validation of the phenotype. Variables that can be used for phenotyping in asthma and COPD include clinical assessments, radiological measures (example, quantitative computerised tomography thorax scans), measures of the inflammatory response, and molecular markers. This review will focus on clinical and inflammatory/molecular phenotyping.

Several different types of study can be used to identify phenotypes. Cross-sectional hypothesis-driven studies assess a predetermined phenotype. For example, the Evaluation of COPD Longitudinally to Identify Predictive Surrogate End-points (ECLIPSE) trial assessed the frequent exacerbator phenotype of $\mathrm{COPD}^{12}$. Hypothesis-free designs, such as cluster analyses, can be used where the data are grouped into categories (phenotypes) based on similarity in the measures used. An example is the cluster analysis of the ECLIPSE study, which identified five phenotypes with differing prognoses ${ }^{13}$. A further possible design is to conduct a responder analysis of a clinical trial and use this to identify a responder phenotype for a particular therapeutic. This approach was successfully used to identify responder characteristics for mepolizumab in severe refractory asthma ${ }^{14}$ and the results showed that low bronchodilator reversibility and nasal polyposis were features of mepolizumab responders, and that this phenotype had a mean $53 \%$ reduction in asthma exacerbation rates with mepolizumab. This is an interesting approach since the link to a clinically meaningful outcome is provided by using a strong study design (i.e. a randomized controlled trial), and the results can provide new insights; for example, finding that low (as opposed to high) bronchodilator reversibility was associated with a large effect size.

Each of these approaches to phenotype identification is dependent on the population studied, how they are selected, and the type and number of variables used for phenotypic assessment. In order to minimize bias and maximize utility, it is necessary to validate findings in a second population where the phenotype can be assessed for stability (repeatability), relation to prognosis, or prediction of response to a specific treatment.

\section{CLINICAL PHENOTYPES OF ASTHMA AND COPD}

There are a number of "clinical phenotypes" that are shared by asthma and COPD. Comorbidities, airway pathophysiology, and risk factors (Table 1, Fig. 1) are key phenotypic characteristics that respond to targeted or individualized therapies (Fig. 1 and 2). Each of these can be readily assessed in the clinic and can be linked to evidenced-based interventions that can be applied to the phenotype. Targeting therapies to the phenotypic characteristics ensures that the right treatments are applied to the right patients, irrespective of their disease diagnosis. This precision medicine approach has been the focus of attention in airways disease. Agusti et al. ${ }^{5}$ have proposed the concept of "treatable traits" of airways disease in a recent review and offer an innovative approach to implementation. We similarly have proposed an approach involving multidimensional 
TABLE 1. Clinical phenotypes of asthma and COPD.

\begin{tabular}{|l|l|}
\hline Comorbidity & $\begin{array}{l}\text { Upper airway dysfunction } \\
\text { Anxiety and depression } \\
\text { Cardiovascular and metabolic disease } \\
\text { Obstructive sleep apnoea } \\
\text { Osteoporosis }\end{array}$ \\
\hline Airway pathophysiology & $\begin{array}{l}\text { Airflow limitation } \\
\text { Acute exacerbations } \\
\text { Airway inflammation }\end{array}$ \\
\hline Risk factors & $\begin{array}{l}\text { Smoking } \\
\text { Physical inactivity } \\
\text { Nutrition (obesity) } \\
\text { Self-management behaviour } \\
\text { Infection }\end{array}$ \\
\hline
\end{tabular}

assessment of the airways, comorbidity, risk factors, and self-management, followed by individualized management based on the identified characteristics ${ }^{4}$. We have piloted this approach in a controlled trial with COPD patients and showed that it leads to significant improvements in health status and outcomes associated with the specified target ${ }^{15}$.

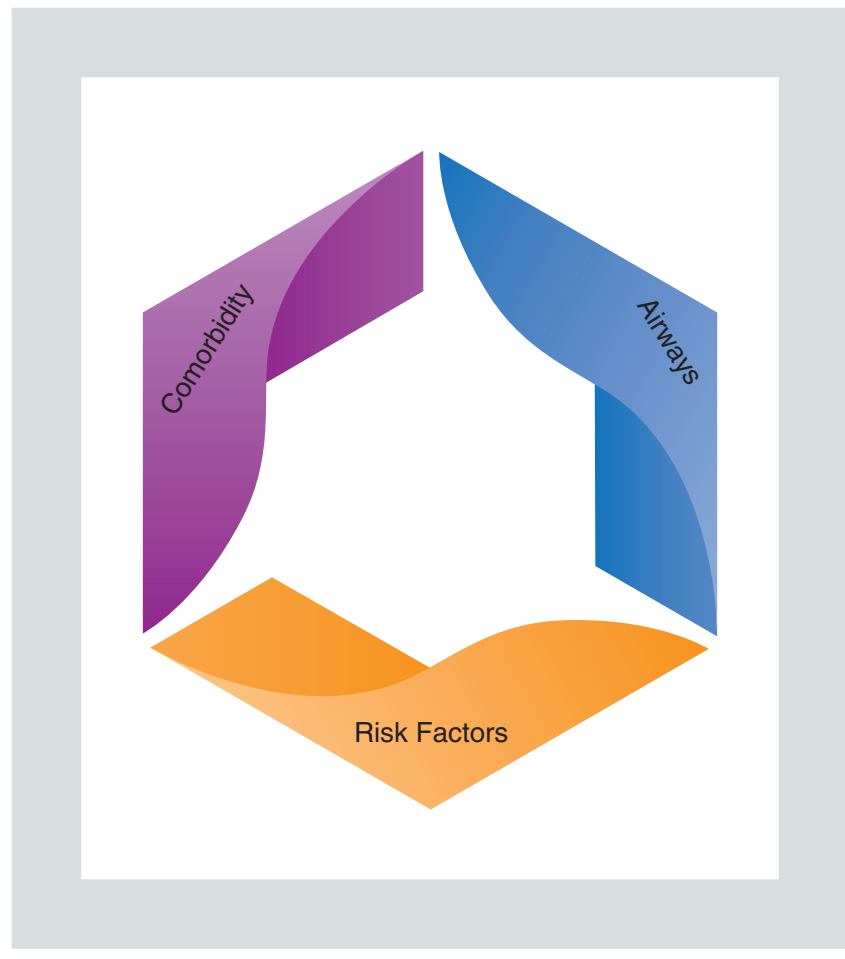

Figure 1. Clinical phenotypes of asthma and COPD ${ }^{\odot}$ (reproduced with permission from Centre of Excellence in Severe Asthma. http://www.severeasthma.org.au/files/2016/09/ CAR.pdf).

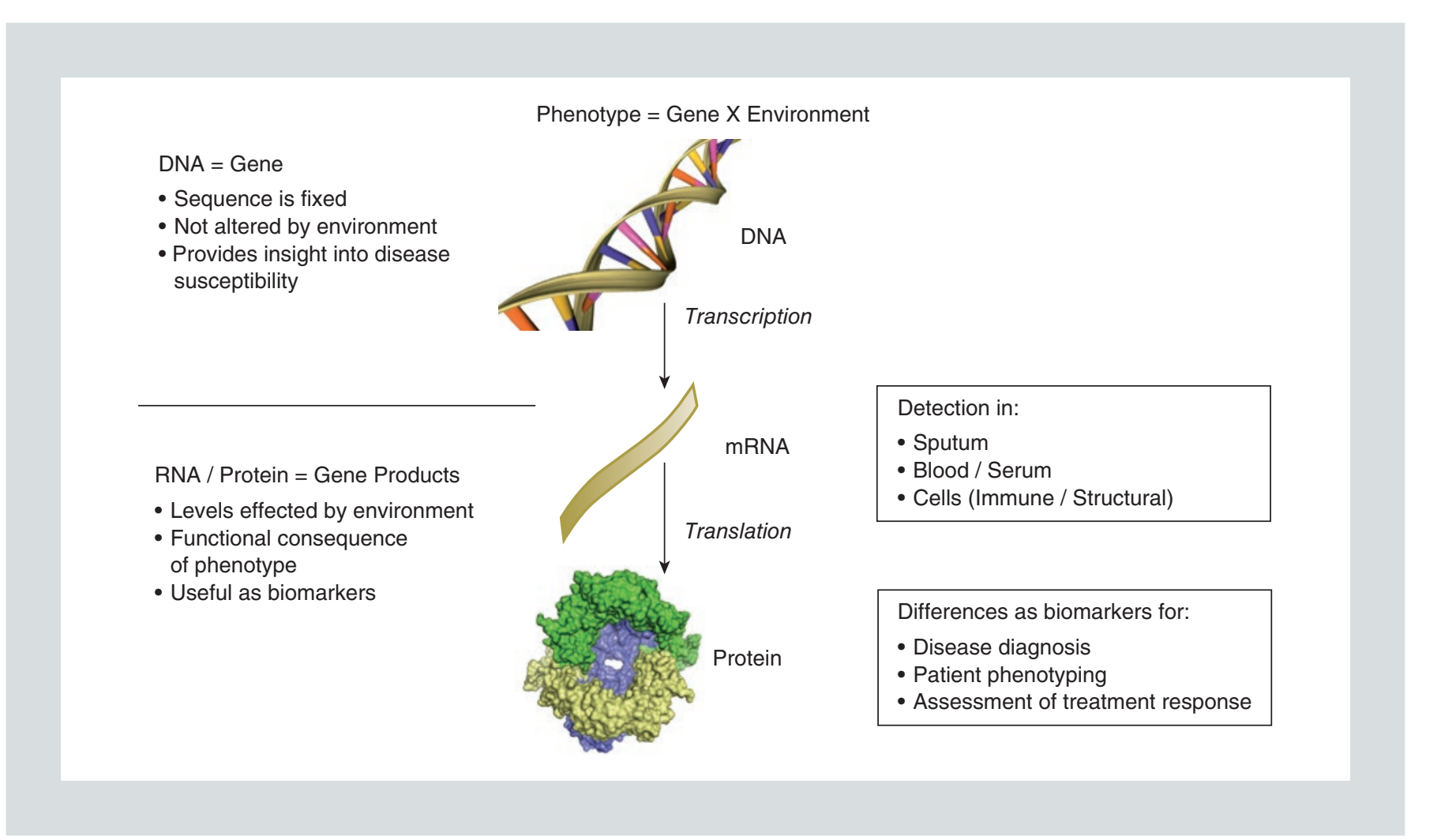

Figure 2. Dissection of a phenotype and the important place of mRNA and protein biomarkers as signs of gene $x$ environment interaction. 


\section{Airway pathophysiology}

\section{Airflow limitation}

Airflow limitation is assessed in the clinic using spirometry to measure forced expiratory volume in one second $\left(\mathrm{FEV}_{1}\right)$, forced vital capacity (FVC), and $\mathrm{FEV}_{1} / \mathrm{FVC}$ ratio. It is important to determine the degree and severity of airflow limitation, and to determine the response to pharmacological treatments that target airflow limitation, including long-acting muscarinic antagonists (LAMA), longacting beta ${ }_{2}$-agonists (LABA), and inhaled corticosteroids (ICS). In asthma, the approach to management includes the initiation and on-going use of ICS \pm LABA, whilst in COPD, first-line treatment involves long-acting bronchodilators followed by the addition of ICS when $\mathrm{FEV}_{1}$ falls below $50 \%$ or the patient becomes a "frequent exacerbator".

\section{EXACERBATIONS}

Exacerbations of asthma and COPD are important events that lead to accelerated decline in lung function, more severe health status impairment, and higher rates of mortality ${ }^{16}$. A frequent-exacerbator phenotype has been described in both asthma ${ }^{17}$ and $\mathrm{COPD}^{12}$ populations. Multiple factors are associated with increased exacerbations, including age, severity of airflow limitation, chronic mucus hypersecretion, bacterial colonization, comorbidity, systemic inflammation, physical inactivity, and smoking; however, the single best predictor of an exacerbation is the experience of a prior one ${ }^{12,17}$. Whether exacerbations should be considered a phenotype or an outcome is a contentious issue. Appropriately, Han et al. ${ }^{9}$ propose that exacerbations can be both, as prior exacerbations relate to clinically meaningful outcomes, e.g. future exacerbations and death, and are also the clinically meaningful outcome for other phenotypes such as the "eosinophilic endotype".

Assessing exacerbations in the clinic is usually performed by asking the patient, and relying on the individuals' recall. While this can give an indication of past history, it is flawed as patients often don't recognise or seek treatment for exacerbations, particularly in $\mathrm{COPD}^{16,18}$. Patient-reported outcome measures are a more robust of approach to measuring exacerbations. The EXAcerbation of COPD Tool (EXACT) has been developed as a measure of frequency, severity and duration of COPD exacerbation and is recommended as a valid outcome measure in clinical trials ${ }^{19}$. However, its use in clinical practice is difficult due to the burden of daily diary monitoring from the patient's perspective. Ensuring patients and clinicians recognize exacerbations of asthma and COPD is essential, as is the development and implementation of multidimensional exacerbation preventive strategies.

\section{Comorbidities}

Both COPD and asthma are associated with many comorbidities. Conditions that are prevalent in both diseases include: upper airway dysfunction, obesity, anxiety and depression, cardiovascular and metabolic disease, obstructive sleep apnoea, and osteoporosis ${ }^{4,20}$ (Table 1). These comorbidities are important determinants of outcome. For instance, in COPD Divo et al. ${ }^{21}$ reported that comorbidities including coronary artery disease, lung cancer, other cancers (oesophageal, pancreatic, and breast cancer 
in females) and anxiety (females) are independently associated with increased risk of death. The use of disease-specific, guideline-based management can be applied in the assessment and management of these comorbidities. Ensuring personalized treatments are implemented is a priority in COPD and asthma.

\section{Risk factors}

A number of behavioural and lifestyle risk factors play an integral role in the development and progression of COPD and asthma. Smoking, physical inactivity, poor nutrition leading to obesity, and poor self-management skills are important clinical phenotypes in both diseases.

\section{Physical activity}

Physical inactivity is an important modifiable risk factor in asthma and COPD and is responsible for major morbidity and mortality worldwide ${ }^{22}$. In COPD, physical inactivity is very common ${ }^{23}$ and one of the greatest predictors of poor outcome ${ }^{24}$. Fewer data exist with respect to physical inactivity in asthma, but in adults it also appears to be common ${ }^{25}$ and associated with poor outcome ${ }^{26}$.

The measure used to assess physical activity is important. Direct questioning will usually underestimate physical inactivity. Validated questionnaires can help quantify activity, but remain subjective. The most reliable measures that are easily accessible from a clinical perspective are actigraphy, the use of pedometers, or activity trackers. Intervention studies in COPD using activity trackers and pedometers suggest that these also lead to increased steps per day ${ }^{23}$.

\section{OBESITY}

Obesity is common in asthma and in COPD and is associated with increased risk of cardiovascular disease, metabolic syndrome, depression, and some cancers. In asthma, weight loss is recommended in overweight and obese individuals and is associated with improved health outcomes, including asthma control and health-related quality of life ${ }^{27}$. In COPD, treatment recommendations are less clear because of the so-called "obesity paradox", whereby individuals who are overweight or obese have improved survival ${ }^{28}$. At present there are no evidenced-based treatment recommendations for obese COPD. However, in a proof of concept study by the present authors, weight loss achieved through meal replacement therapy and dietary counselling coupled with resistance exercise training led to improved COPD outcomes (6-minute walk distance, health-related quality of life, and the body mass index, airflow obstruction, dyspnea, exercise [BODE] index $)^{29}$.

Overweight and obesity can be identified through direct observation and calculation of body mass index (BMI), and this is by far the most common approach in the clinical environment. However, this is not the optimal approach as BMI fails to identify loss of skeletal muscle mass, which is common in chronic respiratory disease. Therefore, assessment of body composition using alternate methods is recommended. This could include assessments that also assess muscle mass (e.g. bio-impedance analysers or dual energy x-ray absorptiometry) to offer a more precise approach to classifying this phenotype. Other options that provide additional information are waist-to-hip ratio and waist 
circumference; these are particularly important when assessing cardiovascular comorbidity risk.

\section{SMOKING}

In people with asthma and COPD, smoking is a risk factor for accelerated lung function decline, impaired corticosteroid response, and increased mortality ${ }^{30}$. Self-report is a commonly used tool to assess smoking; however, it often may result in denial despite on-going smoking. Objective measures, including the use of exhaled carbon monoxide measures and salivary cotinine, are more reliable, and exhaled carbon monoxide can also be used in smoking cessation counselling as a means of demonstrating harm reduction associated with quitting.

Smoking cessation is the targeted treatment for this clinical phenotype and an approach that encompasses a combination of psychosocial interventions and pharmacological interventions, is superior to no treatment or to psychosocial interventions alone ${ }^{31}$.

\section{Self-MANAgement BEHAVIOUR}

Knowledge of disease, optimal inhaler technique, ability to manage exacerbations, and adherence to pharmaco- and non-pharmacotherapies are disease management strategies that reduce the risk of exacerbation, poor symptom control, and future lung function decline. "Poor self-management" could be considered a clinical phenotype. In asthma, self-management education involving written action plans, regular medical review, self monitoring, and enhancement of disease knowledge leads to reduced healthcare utilization and improved patient-reported outcomes $^{32}$. Approaches that activate patients to become successful self-managers are needed in COPD.

\section{INFLAMMATORY ENDOTYPES OF ASTHMA AND COPD}

The pattern of airway inflammation in the airway lumen can be classified based upon the type and proportion of granulocytes present, and these groupings are termed inflammatory endotypes. Four distinct inflammatory endotypes have been identified in asthma and COPD using induced-sputum analysis ${ }^{33,34}$. These are eosinophilic, neutrophilic, mixed granulocytic (eosinophil/neutrophil), and paucigranulocytic. The eosinophilic endotype is present in between 30 and $50 \%$ of people with stable asthma, and between 15 and 30\% of stable COPD patients ${ }^{15,35}$. Eosinophilic airway inflammation has a clearly identified molecular pathway ${ }^{36}$ and has been linked to both prognosis (increased exacerbation rate ${ }^{37,38}$ ) and response to treatment with corticosteroids and anti-interleukin (IL)-5 monoclonal antibodies ${ }^{39,40}$. This makes the eosinophilic endotype one of the best-characterized endotypes. The finding of increased eosinophils in induced sputum ${ }^{41}$ or bronchial biopsy ${ }^{42}$ predicts a good short-term response to corticosteroids in asthma. In COPD, sputum eosinophilia also predicts a good short-term response to corticosteroids ${ }^{43}$. Similarly, longer-term management of asthma and COPD ${ }^{44-48}$ guided by sputum eosinophil counts leads to highly significant reductions in acute exacerbations and health status compared to symptom-based management. Recognition of the 
severe refractory asthma with eosinophilia endotype also predicts a good response to anti-IL-5 monoclonal antibodies (mepolizumab) $39,40,43$.

Since induced sputum is used predominantly as a research tool, more accessible markers are needed in order to recognise the eosinophilic endotype. Potential markers suitable for this are peripheral blood eosinophil counts, fraction of exhaled nitric oxide (FeNO) levels, serum periostin, and their combinations. In persistently symptomatic asthma treated with ICS, a blood eosinophil count above $2.6 \%$, or $0.26 \times 10^{9} / 1$, was an excellent predictor of sputum eosinophilia ${ }^{49}$. In COPD, Bafadel et al. ${ }^{50}$ have reported that a peripheral blood eosinophil count $>2 \%$ is a sensitive biomarker during acute exacerbations to determine sputum eosinophilia ${ }^{50}$. In stable COPD, a threshold of $\geq 0.3 \times 10^{9} / 1$ in peripheral blood eosinophil count enabled identification of the presence or absence of sputum eosinophilia in $71 \%$ of cases $^{35}$. The Withdrawal of Inhaled Steroids During Optimised bronchodilator Management (WISDOM) study was a 12-month, randomized, parallel-group trial of 2,296 COPD patients who received daily tiotropium, salmeterol, and fluticasone propionate for six weeks and were then randomly assigned to either continue treatment or reduce the fluticasone over 12 weeks. A post hoc analysis of these data report that blood eosinophil counts of $\geq 4 \%$ (300 cells per $\mu \mathrm{l}$ ) could be used to identify those that responded deleteriously to ICS withdrawal ${ }^{51}$, suggesting that peripheral blood eosinophils may be a useful marker in guiding therapy in COPD.

An increased FeNO in asthma arises due to increased epithelial inducible nitric oxide synthase (iNOS), and can predict a response to ICS. This marker performs well in mild-tomoderate asthma ${ }^{52}$. Since patients with severe asthma are already treated with high-dose ICS, it may not be discriminatory in that setting $^{53}$. Similarly, the role of FeNO in phenotyping COPD patients requires more research. Serum periostin was identified as a secreted product of IL-13-stimulated bronchial epithelial cells ${ }^{54}$, and has been closely correlated with airway eosinophilia in some ${ }^{55}$, but not all $^{56,57}$, studies. Some ${ }^{58,59}$, but not all ${ }^{57}$, studies suggest a combination of biomarkers gives better prediction of clinical outcomes. Since blood eosinophils are easily accessible, show the best association with airway eosinophilia, and are predictive of treatment response, this biomarker shows great promise for the identification of the eosinophilic endotype in clinical practice.

The neutrophilic endotype is present in approximately $15 \%$ of stable adults with asthma and up to $60 \%$ of COPD patients. It is associated with severe asthma, corticosteroid exposure, fixed airflow limitation ${ }^{60}$, airway dysbiosis $^{61}$, smoking, occupational irritants ${ }^{62}$, and comorbidities such as obesity and sleep apnoea $^{63}$. The proposed molecular pathways include T helper (TH) 17 responses, and NACHT, LRR, and PYD domains containing protein 3 (NLRP3) inflammasome-mediated production of IL-1 $\beta^{64}$, with associated neutrophil activation $^{64,65}$. Further work is needed to define specific treatments for neutrophilic asthma, with macrolide antibiotics ${ }^{66,67}$ showing promise. Peripheral blood markers such as C-reactive protein $^{68}$ and blood neutrophil count ${ }^{49}$ are increased in neutrophilic asthma, but may not be sufficiently discriminatory for use in clinical practice. 


\section{MOLECULAR ENDOTYPES}

The definition of molecular endotypes of asthma and COPD holds great promise. If a molecular pathway can be identified, then the specific components of that pathway can be used as potential treatment targets and also as biomarkers, either to recognize the endotype or to monitor its response to treatment. The identification of molecular endotypes has become increasingly possible with the use of "omics" technologies ${ }^{69-71}$.

A phenotype is defined as the set of observable characteristics of an individual resulting from the interaction of its genotype with the environment. Implicit in this definition is the fact that a phenotype is something more than the genetic makeup of an individual. In practical terms, this means that while a genetic marker may confer some risk, it alone may not be sufficient to allow recognition of a phenotype, and hence prognosis or treatment responsiveness. This means that more information is required that pertains to the "interaction of the genotype with the environment". Whilst deoxyribonucleic acid contains the molecular code, it does not describe the interaction of the organism with its environment that is so crucial to phenotype recognition. So what sort of information describes that interaction? In molecular terms, this interaction comes from the transcription of the genetic code, i.e. as ribonucleic acid, and its translation to protein (Fig. 2). Technologies have been developed that use mass-throughput techniques to define these processes, such as transcriptomics, and proteomics. Several large-scale studies, such as Unbiased BIOmarkers in PREDiction of respiratory disease outcomes (U-BIOPRED) ${ }^{60}$, are underway to integrate these technologies for the characterization of severe asthma.

Transcriptomic analyses in asthma have been conducted to identify asthma endotypes and their relation to clinically relevant outcomes (Table 2). A transcriptomic analysis on induced sputum identified several endotypes with clear molecular differences and correlations with granulocytic subtypes ${ }^{72}$. These markers were further developed into a sixgene signature that reproducibly defined endotype and predicted corticosteroid responsiveness in asthma ${ }^{73}$. Transcriptomic profiling of bronchial epithelial cells identified a three-gene signature for the $\mathrm{TH} 2$ endotype of asthma that yielded a circulating biomarker (periostin) and was predictive of response to ICS ${ }^{54}$. This T2S signature was also found to be present in nasal epithelial brushings and induced sputum ${ }^{74-76}$. The T2S signature was evaluated in asthma/COPD overlap using bronchial brushings and found to be related to bronchodilator and corticosteroid responsiveness ${ }^{77}$. Similarly, a transcriptional analysis of sputum cells identified subtypes that were associated with markers of disease severity, such as lower lung function, hospitalization for asthma, and life-threatening asthma attacks ${ }^{78}$. This profile was also linked to a 53-gene transcript signature in whole blood samples from children with asthma. A transcriptional profiling of macrophages identified gene signatures that were related to asthma severity ${ }^{79}$ and profiling of peripheral cluster of differentiation $4 \mathrm{~T}$ helper $(\mathrm{CD} 4+\mathrm{T})$ cells in asthmatics with and without depression found a signature that was present in depressed asthmatics, and was associated with the degree of airflow limitation ${ }^{80}$. These results show that transcriptomic profiling has successfully identified 
TABLE 2. Transcriptomic profiling for endotypes of asthma

\begin{tabular}{|c|c|c|c|c|}
\hline Author & Disease & Sample & Transcriptomic result & Clinical Correlate \\
\hline Baines et al. ${ }^{73}$ & Asthma & Induced sputum & $\begin{array}{l}\text { 6-gene signature (CPA3, } \\
\text { CLC, DNASEL1, IL1b) }\end{array}$ & $\begin{array}{l}\text { Predicts corticosteroid respon- } \\
\text { siveness } \\
\text { Identifies eosinophilic / neutro- } \\
\text { philic endotypes }\end{array}$ \\
\hline $\begin{array}{l}\text { Woodruff et al. }{ }^{54} \\
\text { Peters et al. } \\
\text { Poole et al. }{ }^{76}\end{array}$ & Asthma & $\begin{array}{l}\text { Bronchial epithelial cells } \\
\text { Induced sputum } \\
\text { Nasal epithelial cells }\end{array}$ & $\begin{array}{l}\text { T2 signature - T2S } \\
\text { (PSTN, CLCA1, SERPINB2) }\end{array}$ & $\begin{array}{l}\text { Predicts corticosteroid respon- } \\
\text { siveness }\end{array}$ \\
\hline Yan et al. ${ }^{78}$ & Asthma & Induced sputum / blood & $\begin{array}{l}3 \text { endotypes, } 53 \text { gene profile } \\
\text { (EXOSC9, SMAPC5, NRCAM, } \\
\text { PCLO, DNAH17, DEFB1) }\end{array}$ & $\begin{array}{l}\text { Associated with asthma } \\
\text { hospitalisations and near-fatal } \\
\text { asthma }\end{array}$ \\
\hline Wang et al..$^{80}$ & Asthma & Circulating $\mathrm{CD}^{+} \mathrm{T}$-cells & CYP2D $\gamma$, PIK3R1, CFB & $\begin{array}{l}\text { Asthma and depression } \\
\text { Airflow obstruction }\end{array}$ \\
\hline Becker et al. ${ }^{79}$ & Asthma & $\begin{array}{l}\text { Human MDM } \\
\text { Bronchoalveolar lavage macrophages } \\
\text { Bronchial biopsies }\end{array}$ & $\begin{array}{l}\text { M (IFN } \gamma+\text { LPS, TNF } \alpha) \\
\text { M (IL-4, IL-13) } \\
\text { RAMP1 }\end{array}$ & Asthma severity \\
\hline Christensen et al. ${ }^{77}$ & $\begin{array}{l}\text { Asthma-COPD } \\
\text { overlap }\end{array}$ & Bronchial brushings / epithelium & POSTN, CLCA1, SERPINB2 & $\begin{array}{l}\text { Airflow obstruction } \\
\text { Bronchodilator reversibility } \\
\text { Corticosteroid response }\end{array}$ \\
\hline
\end{tabular}

CPA3: Carboxypeptidase A3; CLC: Charcot-Leyden crystal; DNASEL1: DNase I-Like 1; IL1b: Interleukin 1 beta; T2S: type 2 Signature; PSTN: Periostin; CLCA1: Chloride channel accessory 1; SERPINB2: Serpin Family B Member 2; EXOSC9: Exosome Component 9; SNAPC5: Small nuclear RNA activating complex, polypeptide 5; NRCAM: Neuronal Cell Adhesion Molecule; PCLO: Piccolo Presynaptic Cytomatrix Protein; DNAH17: Dynein Axonemal Heavy Chain 17; DEFb1: Defensin Beta 1; CYP2D $\gamma$ : cytochrome P450, family 2, subfamily D, polypeptide 6; PIK3R1: Phosphoinositide-3- Kinase Regulatory Subunit 1; CFB: complement factor B; M (IFN $\gamma+$ LPS, TNF $\alpha$ ): macrophage (Interferon gamma + Lipopolysaccharide, Tumor necrosis factor alpha); M (IL-4, IL-13): macrophage (interleukin 4, interleukin 13); RAMP1: Receptor activity modifying protein 1;

POSTN: periostin

molecular endotypes of asthma using a variety of samples, and that these associate with clinically important outcomes. Further development of this approach will require confirmation in larger patient numbers and increasing the accessibility of the testing.

\section{INTEGRATION}

How do we put it all together?

A COPD control panel has been proposed by Agusti and $\mathrm{MacNee}^{6}$; this panel includes three domains that relate to severity, activity and impact. Within each domain are elements that provide information that can guide individualized management of the COPD. We have previously proposed a model of airways disease management that includes the domains of the airways, comorbidity, risk factors, and self-management skills ${ }^{4}$. We have now proposed an airway disease phenotype panel based on currently available research results, accessible measurements, and available therapies (Table 3, Fig. 1 and 3). This can include assessment of airway pathophysiology (airflow limitation, eosinophilia and exacerbations), comorbidity, and risk factors. Each of these domains can be linked to a specific and effective therapeutic approach (Table 3). Several questions remain regarding whether patient assessment and treatment should involve concurrent or sequential assessment 


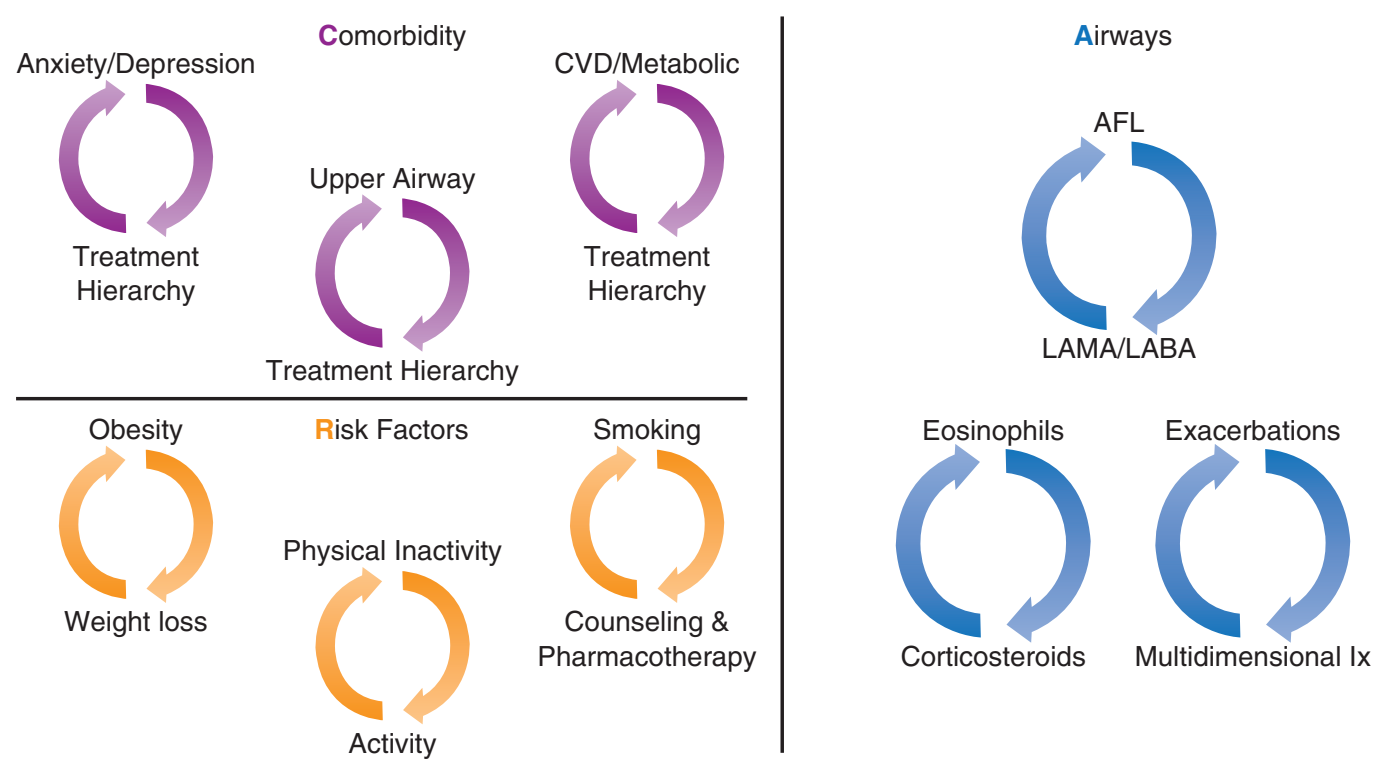

FiguRE 3. Targeted treatment cascade for asthma and COPD.

AFL: airflow limitation; CVD: cardiovascular disease; LABA: long-acting Beta ${ }_{2}$ agonists; LAMA: long-acting muscarinic antagonists; Multidimensional Ix: multidimensional intervention.

TABLE 3. Phenotype assessment and treatment in asthma and COPD

\begin{tabular}{|c|c|c|c|}
\hline \multirow[t]{2}{*}{ Panel } & \multicolumn{2}{|c|}{ Measurement } & \multirow[t]{2}{*}{ Interventions } \\
\hline & Simple & Involved & \\
\hline \multicolumn{4}{|l|}{ Airway pathophysiology } \\
\hline Airflow limitation & Spirometry & Lung volumes & Long-acting bronchodilators \\
\hline Exacerbations & History & $\begin{array}{l}\text { Validated patient-reported outcome } \\
\text { measure }\end{array}$ & $\begin{array}{l}\text { Bronchodilators } \\
\text { Corticosteroids } \\
\text { Address risk factors }\end{array}$ \\
\hline Eosinophilia & Blood count & $\begin{array}{l}\text { Induced sputum } \\
\text { T2 Subtypes } \\
6 \text { gene signature }\end{array}$ & $\begin{array}{l}\text { Corticosteroid } \\
\text { Anti-IL-5 therapy }\end{array}$ \\
\hline Comorbidity & History & COTE $^{21}$ & Guideline-based therapy \\
\hline \multicolumn{4}{|l|}{ Risk factors } \\
\hline Smoking & History & Exhaled carbon monoxide & Smoking cessation (counselling and pharmacotherapy) \\
\hline Physical inactivity & History & Actigraphy & Physical activity, behaviour change strategies \\
\hline Nutrition - Obesity & BMI & $\begin{array}{l}\text { DEXA or BIA (body composition) } \\
\text { Waist-to-hip ratio, waist circumference }\end{array}$ & Weight loss \\
\hline Poor self management & History & Direct observation & Self-management education \\
\hline Infection & History & & $\begin{array}{l}\text { Vaccination } \\
\text { Infection prevention strategies (avoidance, hand hygiene) }\end{array}$ \\
\hline
\end{tabular}

BIA: bio-impedance analysis; BMI: body mass index; COTE: COPD-specific comorbidity test; DEXA: dual energy X-Ray absorptiometry. 


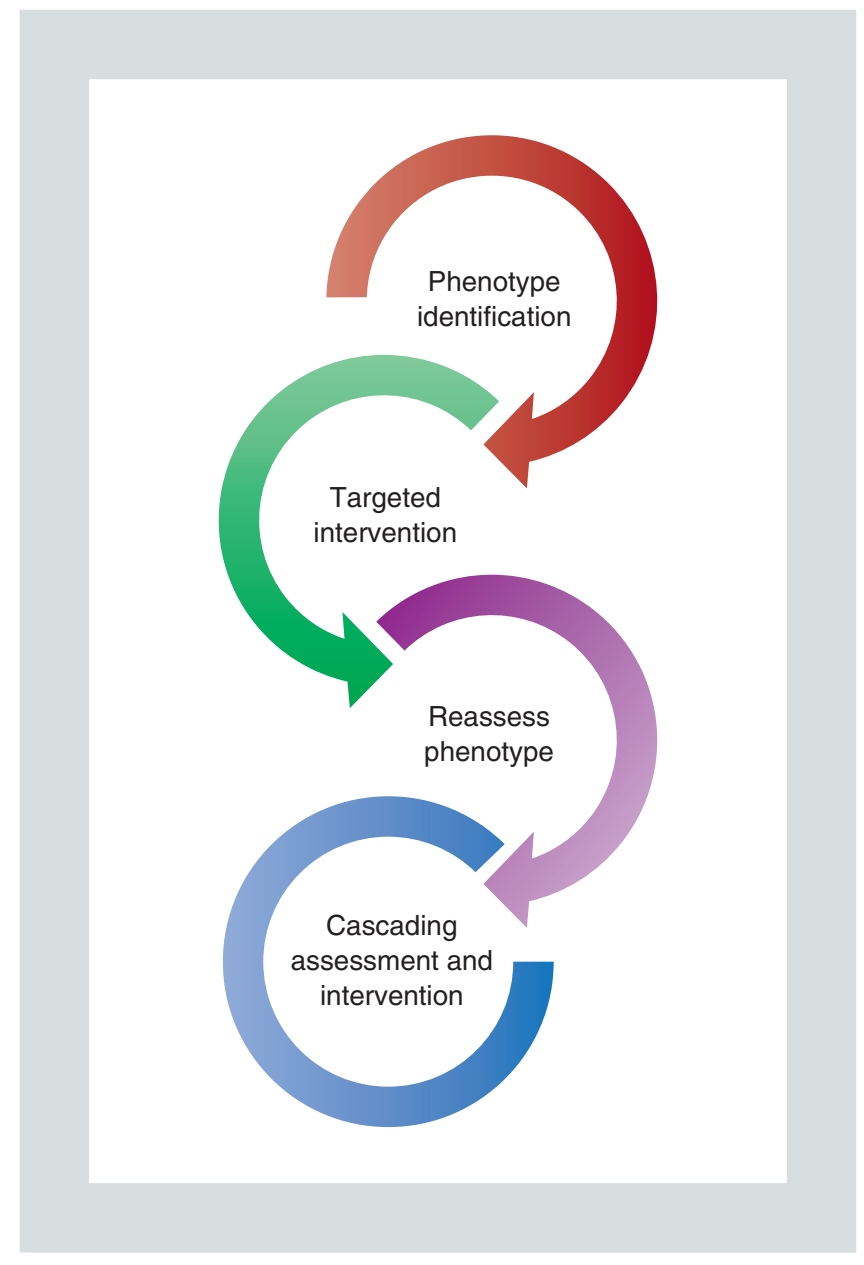

Figure 4. CARe cascade.

and treatment of all domains (Fig. 4). A concurrent approach is appealing for those domains that are easily accessible and simply treated. The assessment can then be reapplied, and if the patient shows an incomplete response, more intensive assessment and therapy can be introduced. This results in a cascade of assessment and intervention, moving from simple to more complex.

\section{CONCLUSION}

\section{Asthma and COPD are common obstructive airway diseases. Assessment and manage- ment in clinical practice is often confounded}

by the complex heterogeneity that underlies these conditions. An approach is offered that involves phenotyping patients and linking these observed traits to evidence-based management. Research has identified useful ways to phenotype some traits, and studies are now required to demonstrate the efficacy of this treatment approach.

\section{REFERENCES}

1. Buist SA, McBurnie MA, Vollmer WM et al. International variation in the prevalence of COPD (The BOLD Study): a population-based prevalence study. Lancet. 2007;370:741-50.

2. Toelle BG, Xuan W, Bird TE et al. Respiratory symptoms and illness in older Australians: the Burden of Obstructive Lung Disease (BOLD) study. Med J Aust. 2013;198:144-8.

3. Lozano R, Naghavi M, Foreman K et al. Global and regional mortality from 235 causes of death for 20 age groups in 1990 and 2010: a systematic analysis for the Global Burden of Disease Study 2010. Lancet. 2012;380:2095-128.

4. Gibson PG, McDonald VM, Marks GB. Asthma in the Older Adult. Lancet. 2010;374:803-13.

5. Agusti A, Bel E, Thomas M et al. Treatable traits: toward precision medicine of chronic airway diseases. Eur Respir J. 2016;47:410-9.

6. Agusti A, MacNee W. The COPD control panel: towards personalised medicine in COPD. Thorax. 2013;68:687-90.

7. McDonald VM, Higgins I, Gibson PG. Managing older patients with coexistent asthma and COPD: diagnostic and therapeutic challenges. Drugs Aging. 2013;30:1-17.

8. Agusti A. The path to personalised medicine in COPD. Thorax. 2014;69: 857-64.

9. Han MK, Agusti A, Calverley PM et al. Chronic obstructive pulmonary disease phenotypes: the future of COPD. Am J Respir Crit Care Med. 2010;182:598-604.

10. Anderson GP. Endotyping asthma: new insights into key pathogenic mechanisms in a complex, heterogeneous disease. Lancet. 2008;372:1107-19.

11. Lotvall J, Akdis CA, Bacharier LB et al. Asthma endotypes: a new approach to classification of disease entities within the asthma syndrome. J Allergy Clin Immunol. 2011;127:355-60.

12. Hurst JR, Vestbo J, Anzueto A et al. Susceptibility to exacerbation in chronic obstructive pulmonary disease. N Engl J Med. 2010;363:1128-38.

13. Rennard SI, Locantore N, Delafont B et al. Identification of five chronic obstructive pulmonary disease subgroups with different prognoses in the ECLIPSE cohort using cluster analysis. Ann Am Thorac Soc. 2015;12:303-12.

14. Ortega H, Li H, Suruki R, Albers F, Gordon D, Yancey S. Cluster analysis and characterization of response to mepolizumab. A step closer to personalized medicine for patients with severe asthma. Ann Am Thorac Soc. 2014;11:1011-7.

15. McDonald VM, Higgins I, Wood LG, Gibson PG. Multidimensional assessment and tailored interventions for COPD: respiratory utopia or common sense? Thorax. 2013;68:691-4.

16. Pavord ID, Jones PW, Burgel PR, Rabe KF. Exacerbations of COPD. Int J Chron Obstruct Pulmon Dis. 2016;11:21-30.

17. Miller MK, Lee JH, Miller DP, Wenzel SE. Recent asthma exacerbations: a key predictor of future exacerbations. Respir Med. 2007;101:481-9.

18. Jones PW, Lamarca R, Chuecos F et al. Characterisation and impact of reported and unreported exacerbations: results from ATTAIN. Eur Respir J. 2014;44:1156-65. 
19. Leidy NK, Sexton CC, Jones PW et al. Measuring respiratory symptoms in clinical trials of COPD: reliability and validity of a daily diary. Thorax. 2014;69:443-9.

20. Negewo NA, Gibson PG, McDonald VM. COPD and its comorbidities: Impact, measurement and mechanisms. Respirology. 2015;20:1160-71.

21. Divo M, Cote C, de Torres JP et al. Comorbidities and risk of mortality in patients with chronic obstructive pulmonary disease. Am J Respir Crit Care Med. 2012;186:155-61.

22. Lee IM, Shiroma EJ, Lobelo F, Puska P, Blair SN, Katzmarzyk PT. Effect of physical inactivity on major non-communicable diseases worldwide: an analysis of burden of disease and life expectancy. Lancet. 2012;380: 219-29.

23. Mantoani LC, Rubio N, McKinstry B, MacNee W, Rabinovich RA. Interventions to modify physical activity in patients with COPD: a systematic review. Eur Respir J. 2016;48:69-81.

24. Waschki B, Kirsten A, Holz O et al. Physical activity is the strongest predictor of all-cause mortality in patients with COPD: a prospective cohort study. Chest. 2011;140:331-42.

25. Ford ES, Heath GW, Mannino DM, Redd SC. Leisure-time physical activity patterns among US adults with asthma. Chest. 2003;124:432-7.

26. Strine TW, Balluz LS, Ford ES. The associations between smoking, physical inactivity, obesity, and asthma severity in the general US population. J Asthma. 2008;44:651-8.

27. Scott HA, Gibson PG, Garg ML et al. Dietary restriction and exercise improve airway inflammation and clinical outcomes in overweight and obese asthma: a randomized trial. Clin Exp Allergy. 2013;43:36-49.

28. Landbo C, Prescott E, Lange P T, Vestbo J, Almdal TP. Prognostic value of nutritional status in chronic obstructive pulmonary disease. Am J Respir Crit Care Med. 1999;160:1856-61.

29. McDonald VM, Gibson PG, Scott HA et al. Should we Treat Obesity in COPD? The Effects of Diet and Resistance Exercise Training. Respirology. 2016;21:875-82

30. Bellia V, Battahlia S, Catalano F et al. Aging and disability affect misdiagnosis of COPD in elderly asthmatics. Chest. 2003;123:1066-72.

31. van der Meer RM, Wagena EJ, Ostelo RW, Jacobs JE, van Schayck CP. Smoking cessation for chronic obstructive pulmonary disease. Cochrane Database Syst Rev. 2001:CD002999.

32. Gibson PG, Powell H, Coughlin J et al. Self-management education and regular practitioner review for adults with asthma. Cochrane Database Syst Rev. 2003:CD001117.

33. Simpson JL, Scott R, Boyle MJ, Gibson PG. Inflammatory subtypes in asthma: assessment and identification using induced sputum. Respirology. 2006; 11:54-61.

34. McDonald VM, Simpson JL, Higgins I, Gibson PG. Multidimensional assessment of older people with asthma \& COPD: Clinical management and health status. Age Ageing. 2011;40:42-9.

35. Negewo NA, McDonald VM, Baines KJ et al. Peripheral blood eosinophils: a surrogate marker for airway eosinophilia in stable COPD. Int J COPD. 2016;11:1495-504.

36. Agache I, Strasser DS, Klenk A et al. Serum IL-5 and IL-13 consistently serve as the best predictors for the blood eosinophilia phenotype in adult asthmatics. Allergy. 2016;71:1192-202.

37. McDonald VM, Gibson PG. Exacerbations of severe asthma. Clin Exp Allergy. 2012;42:670-7.

38. Walsh CJ, Zaihra T, Benedetti A et al. Exacerbation risk in severe asthma is stratified by inflammatory phenotype using longitudinal measures of sputum eosinophils. Clin Exp Allergy. 2016. [Epub ahead of print]

39. Haldar P, Brightling CE, Hargadon B et al. Mepolizumab and exacerbations of refractory eosinophilic asthma. N Engl J Med. 2009;360:973-84.

40. Nair P, Pizzichini MM, Kjarsgaard M et al. Mepolizumab for prednisone-dependent asthma with sputum eosinophilia. N Engl J Med. 2009;360: 985-93.

41. Louis RE, Joos GF. Eosinophilia and chronic airway disease. BRN Rev. 2016; 2:143-58
42. Berry M, Morgan A, Shaw DE et al. Pathological features and inhaled corticosteroid response of eosinophilic and non-eosinophilic asthma. Thorax. 2007;62:1043-9.

43. Kitaguchi Y, Komatsu Y, Fujimoto K, Hanaoka M, Kubo K. Sputum eosinophilia can predict responsiveness to inhaled corticosteroid treatment in patients with overlap syndrome of COPD and asthma. Int J Chron Obstruct Pulmon Dis. 2012;7:283-9.

44. Green RH, Brightling CE, McKenna Set al. Asthma exacerbations and sputum eosinophil counts: a randomised controlled trial. Lancet. 2002;360:1715-21.

45. Jayaram L, Pizzichini MM, Cook RJ et al. Determining asthma treatment by monitoring sputum cell counts: effect on exacerbations. Eur Respir J. 2006;27:483-94

46. Chlumsky J, Striz I, Terl M, Vondracek J. Strategy aimed at reduction of sputum eosinophils decreases exacerbation rate in patients with asthma. J Int Med Res. 2006;34:129-39.

47. Petsky HL, Cates CJ, Lasserson TJ et al. A systematic review and meta-analysis: tailoring asthma treatment on eosinophilic markers (exhaled nitric oxide or sputum eosinophils). Thorax. 2012;67:199-208.

48. Siva R, Green RH, Brightling CE et al. Eosinophilic airway inflammation and exacerbations of COPD: a randomised controlled trial. Eur Respir J. 2007;29:906-13.

49. Zhang XY, Simpson JL, Powell H et al. Full blood count parameters for the detection of asthma inflammatory phenotypes. Clin Exp Allergy. 2014;44: 1137-45.

50. Bafadhel M, McKenna S, Terry S et al. Acute exacerbations of chronic obstructive pulmonary disease: identification of biologic clusters and their biomarkers. Am J Respir Crit Care Med. 2011;184:662-71.

51. Watz H, Tetzlaff K, Wouters EF et al. Blood eosinophil count and exacerbations in severe chronic obstructive pulmonary disease after withdrawal of inhaled corticosteroids: a post-hoc analysis of the WISDOM trial. Lancet Respir Med. 2016;4:390-8.

52. Powell H, Murphy VE, Taylor DR et al. Management of asthma in preg nancy guided by measurement of fraction of exhaled nitric oxide: a double-blind, randomised controlled trial. Lancet. 2011;378:983-90.

53. Nair P, Kjarsgaard M, Armstrong S, Efthimiadis A, O'Byrne PM, Hargreave FE. Nitric oxide in exhaled breath is poorly correlated to sputum eosinophils in patients with prednisone-dependent asthma. J Allergy Clin Immunol. 2010;126:404-6.

54. Woodruff PG, Boushey HA, Dolganov GM et al. Genome-wide profiling identifies epithelial cell genes associated with asthma and with treatmen response to corticosteroids. Proc Nat Acad Sci USA. 2007;104:15858-63.

55. Jia G, Erickson RW, Choy DF et al. Periostin is a systemic biomarker of eosinophilic airway inflammation in asthmatic patients. J Allergy Clin Immunol. 2012;130:647-54.

56. Simpson JL, Yang IA, Upham JW et al. Periostin levels and eosinophilic inflammation in poorly-controlled asthma. BMC Pulmon Med. 2016;16:67.

57. Wagener AH, de Nijs SB, Lutter R et al. External validation of blood eosinophils, $\mathrm{FE}(\mathrm{NO})$ and serum periostin as surrogates for sputum eosinophils in asthma. Thorax. 2015;70:115-20.

58. Cowan DC, Taylor DR, Peterson LE et al. Biomarker-based asthma phenotypes of corticosteroid response. J Allergy Clin Immunol. 2015;135:877-83.

59. Malinovschi A, Janson C, Borres M, Alving K. Simultaneously increased fraction of exhaled nitric oxide levels and blood eosinophil counts relate to increased asthma morbidity. J Allergy Clin Immunol. 2016. [Epub ahead of print].

60. Shaw DE, Sousa AR, Fowler SJ et al. Clinical and inflammatory characteristics of the European U-BIOPRED adult severe asthma cohort. Eur Respir J. 2015;46:1308-21.

61. Simpson JL, Daly J, Baines KJ et al. Airway dysbiosis: Haemophilus influenzae and Tropheryma in poorly controlled asthma. Eur Respir J. 2016;47 792-800.

62. Simpson JL, Guest M, Boggess MM, Gibson PG. Occupational exposures, smoking and airway inflammation in refractory asthma. BMC Pulmon Med. 2014;14:207. 
63. Teodorescu M, Broytman O, Curran-Everett D et al. Obstructive sleep apnea risk, asthma burden, and lower airway inflammation in adults in the Severe Asthma Research Program (SARP) II. J Allergy Clin Immunol. 2015; 3:566-75.

64. Kim RY, Pinkerton JW, Gibson PG, Cooper MA, Horvat JC, Hansbro PM. Inflammasomes in COPD and neutrophilic asthma. Thorax. 2015;70:1199201.

65. Wright TK, Gibson PG, Simpson JL, McDonald VM, Wood LG, Baines KJ. Neutrophil extracellular traps are associated with inflammation in chronic airway disease. Respirology. 2016;21:467-75.

66. Essilfie AT, Horvat JC, Kim RY et al. Macrolide therapy suppresses key features of experimental steroid-sensitive and steroid-insensitive asthma. Thorax. 2015;70:458-67.

67. Simpson JL, Powell H, Boyle MJ, Scott RJ, Gibson PG. Clarithromycin targets neutrophilic airway inflammation in refractory asthma. Am J Respir Crit Care Med. 2008;177:148-55.

68. Wood LG, Baines KJ, Fu J, Scott HA, Gibson PG. The neutrophilic inflammatory phenotype is associated with systemic inflammation in asthma. Chest. 2012;142:86-93.

69. Wenzel SE. Emergence of biomolecular pathways to define novel asthma phenotypes. Type-2 immunity and beyond. Am J Respir Cell Molec Biol. 2016;55:1-4.

70. Benson M. Clinical implications of omics and systems medicine: focus on predictive and individualized treatment. J Intern Med. 2016;279:229-40.

71. Persson H, Kwon AT, Ramilowski JA et al. Transcriptome analysis of controlled and therapy-resistant childhood asthma reveals distinct gene expression profiles. J Allergy Clin Immunol. 2015;136:638-48.
72. Baines KJ, Simpson JL, Wood LG, Scott RJ, Gibson PG. Transcriptional phenotypes of asthma defined by gene expression profiling of induced sputum samples. J Allergy Clin Immunol. 2011;127:153-60.

73. Baines KJ, Simpson JL, Wood LG et al. Sputum gene expression signature of 6 biomarkers discriminates asthma inflammatory phenotypes. J Allergy Clin Immunol. 2014;133:997-1007.

74. Peters MC, Mekonnen ZK, Yuan S, Bhakta NR, Woodruff PG, Fahy JV. Measures of gene expression in sputum cells can identify TH2-high and TH2-low subtypes of asthma. J Allergy Clin Immunol. 2014;133:388-94.

75. Bhakta NR, Solberg OD, Nguyen CP et al. A qPCR-based metric of Th2 airway inflammation in asthma. Clin Transl Allergy. 2013;3:24.

76. Poole A, Urbanek C, Eng C et al. Dissecting childhood asthma with nasal transcriptomics distinguishes subphenotypes of disease. J Allergy Clinical Immunol. 2014;133:670-8.

77. Christenson SA, Steiling K, van den Berge M et al. Asthma-COPD overlap. Clinical relevance of genomic signatures of type 2 inflammation in chronic obstructive pulmonary disease. Am J Respir Crit Care Med. 2015 191:758-66.

78. Yan X, Chu JH, Gomez J et al. Noninvasive analysis of the sputum transcriptome discriminates clinical phenotypes of asthma. Am J Respir Crit Care Med. 2015;191:1116-25.

79. Becker M, De Bastiani MA, Parisi MM et al. Integrated transcriptomics establish macrophage polarization signatures and have potential applications for clinical health and disease. Sci Rep. 2015;5:13351.

80. Wang T, Ji YL, Yang YY et al. Transcriptomic profiling of peripheral blood CD4(+) T-cells in asthmatics with and without depression. Gene. 2015;565 282-7. 